\title{
Determination of car on-road black carbon and particle number emission factors and comparison between mobile and stationary measurements
}

\author{
I. Ježek ${ }^{1}$, L. Drinovec ${ }^{1}$, L. Ferrero ${ }^{2}$, M. Carriero ${ }^{3}$, and G. Močnik ${ }^{1}$ \\ ${ }^{1}$ Aerosol d.o.o., Kamniška 41, 1000 Ljubljana, Slovenia \\ ${ }^{2}$ POLARIS research center, Department of Environmental Sciences, University of Milano-Bicocca, Piazza della Scienza 1, \\ 20126 Milano, Italy \\ ${ }^{3}$ European Commission, Joint Research Centre (JRC), Ispra, Italy
}

Correspondence to: I. Ježek (irena.jezek@aerosol.si) and G. Močnik (grisa.mocnik@aerosol.si)

Received: 6 March 2014 - Published in Atmos. Meas. Tech. Discuss.: 3 June 2014

Revised: 24 October 2014 - Accepted: 17 November 2014 - Published: 6 January 2015

\begin{abstract}
We have used two methods for measuring emission factors (EFs) in real driving conditions on five cars in a controlled environment: the stationary method, where the investigated vehicle drives by the stationary measurement platform and the composition of the plume is measured, and the chasing method, where a mobile measurement platform drives behind the investigated vehicle. We measured EFs of black carbon and particle number concentration. The stationary method was tested for repeatability at different speeds and on a slope. The chasing method was tested on a test track and compared to the portable emission measurement system. We further developed the data processing algorithm for both methods, trying to improve consistency, determine the plume duration, limit the background influence and facilitate automatic processing of measurements. The comparison of emission factors determined by the two methods showed good agreement. EFs of a single car measured with either method have a specific distribution with a characteristic value and a long tail of super emissions. Measuring EFs at different speeds or slopes did not significantly influence the EFs of different cars; hence, we propose a new description of vehicle emissions that is not related to kinematic or engine parameters, and we rather describe the vehicle EF with a characteristic value and a super emission tail.
\end{abstract}

\section{Introduction}

Regulation of particulate air pollution addresses the health and climate effects of aerosolized matter (Ferrero et al., 2014; Ramanathan and Feng, 2009; Pope et al., 2009). One of the main sources of air pollution is traffic. To estimate the traffic contribution to air pollution different methods can be used (Perrone et al., 2013; Moroni et al., 2012; Kuhns et al., 2004). The bottom-up approach attempts to calculate the emissions from the vehicle fleet composition and vehicle emission factors (EFs); however, the difficulty of these methods lies in the details of the different vehicle types used such as vehicle types (cars, heavy and light duty), the maintenance of engines, their use in different environments (city, highway, regional roads) and weather conditions.

There have been many tests and statistical analyses performed on different vehicles and driving parameters to include these variables to the highest possible degree. Franco et al. (2013) summarized these in their review of EF development. They define EF as different empirical functional relations of emitted pollutants to the activity that causes them. Most standardized and robust EFs were found to be produced in laboratories using dynamometer tests with prescribed driving cycles. These tests can produce aggregated or bag results with respect to mean speed or some other kinematic parameter (e.g., mean acceleration) of a driving cycle, or instantaneous emission data, where measured emissions values can be related to recorded instantaneous kinematic or engine covariates (Perrone et al., 2014). 
The estimation of vehicle emissions increased in complexity as emission regulations came into effect; before regulation emissions were high and well correlated with vehicle average speed, whereas after the introduction of newer and more sophisticated engines and aftertreatment systems, vehicle emission factors were no longer correlated to average driving speed (Ntziachristos and Samaras, 2000) and the instantaneous approach became more difficult to apply as well (de Haan and Keller, 2004). Ajtay et al. (2005) and Weilenmann et al. (2001) found that the measured engine parameters and emission measurements diverge as the exhaust gas is transported through the car, sampling lines and analyzers, resulting in up to a $15 \mathrm{~s}$ delayed and broadened exhaust parameters. They found that further discrepancies arise from incompatible time resolutions of emission and engine-related measurements: the time characteristic for emission-related parameters depends on the operation of the engine and is on the order of magnitude of several tenths of a second, contrasting most emission-related measurements which operate on a $1 \mathrm{~s}$ time base.

In order to validate emission model predictions and to compare their performance to actual vehicle emissions, socalled real-world EF measurement techniques have been developed (Franco et al., 2013). These employ different techniques for measuring numerous in-use vehicles in actual traffic situations; for example, measurements were performed on-road by employing remote-sensing, chasing or on-board detection or in tunnels (some of the first such experiments were of Hansen and Rosen, 1990; Bishop et al., 1996; Weingartner et al., 1997).

The real-world methods have been described as less precise than the dynamometer studies because the tests are not as repeatable as dynamometer ones due to absence of standard cycles and presence of additional source of variability, such as environmental or traffic conditions, driver behavior or highly transient operation (Franco et al., 2013). However, we believe these measured EFs could be a beneficial addition to models, when they are properly incorporated with real-world emission measurements of a large number of random in-use vehicles resulting in a proper representation of the whole vehicle fleet emissions.

Black carbon (BC) and particle number concentrations (PNs) show direct or indirect health and climate effects (e.g., Bond et al., 2013; Janssen et al., 2011; Vinzents et al., 2005, and references therein). Legislation, however, limits the particle mass concentration (PM) both at the sources of emissions, e.g., with vehicle emission standards and in ambient concentrations (2008/50/EC, 2008).

European emission standards for passenger cars nominally referred to as Euro 1 to Euro 6 were first introduced in 1991 in the Directive 91/441/EEC. At that time regulations applied only to emissions of $\mathrm{CO}$, hydrocarbons and $\mathrm{NO}_{\mathrm{x}}$ for gasoline cars, and additionally PM for diesel cars. Since then, the allowed emission levels of each regulated pollutant have been gradually decreased, and more pollutants have been intro- duced into the regulations. For the Euro 3 stage (Directive 98/69/EC, 1998), $\mathrm{NO}_{\mathrm{x}}$ levels were prescribed for both gasoline and diesel cars, and total hydrocarbons emission levels were introduced for gasoline cars only. With Euro 5 (Directive 715/2007/EC, 2007) additional non-methane hydrocarbons and PM levels were set for gasoline cars and PNs for both gasoline and diesel cars were declared to be set no later than upon entry into force of Euro 6 regulations. The emission limits were determined by considering the best available or predicted technology. Only new vehicles that are to be sold in the European market are tested for compliancy. The directive allows for a transitional period for manufacturers, where they can choose under which directive they want their vehicles approved. Euro emission standards do not apply to vehicles that are already in use.

Here a comparison of two methods for measuring the realworld BC and PN EFs of a single vehicle is presented. The first method is the stationary method, where EFs are calculated from the instantaneous rise of pollutants when a vehicle passes the measuring station (Hansen and Rosen, 1990; Ban-Weis et al., 2009; Dallmann et al., 2011); the second method is the chasing method, where vehicle emissions are measured by driving a mobile station behind the measured vehicle on the road (Wang et al., 2011, 2012). Both methods assume equal dilution of all emitted pollutants and use the carbon balance equation to calculate the EF as the pollutant mass per kilogram fuel consumed. Assuming complete combustion of fuel, where almost all carbon in fuel is oxidized to $\mathrm{CO}_{2}$ (Hansen et al., 1990; Ban-Weis et al., 2009; Dallmann et al., 2011), the fuel consumption can be estimated by measuring the $\mathrm{CO}_{2}$ emissions. Wang et al. (2011) also considered $\mathrm{CO}$, unburned hydrocarbons and soot to obtain a more accurate $\mathrm{EF}$; however, it has been demonstrated by Dallmann et al. (2011) that omitting these from the calculation yields only a $5 \%$ positive bias in calculated EFs.

When considering vehicle emissions, the EFs are most often reported in mass of pollutant per kilometer driven, where measured emissions are related to the distance the vehicle traveled. This type of reporting is used for the determination of the compliance of new vehicles with the European emission standards and in emission modeling. The on-road methods measure the EF as a mass of pollutant emitted per mass of fuel consumed. The relation of the EF in pollutant per kilometer to EF in pollutant per kilogram fuel consumed can be done by estimating fuel consumption and fuel density.

To improve the knowledge on real-world EFs, we applied these methods, so far used on heavy-duty vehicles and preEuro one passenger cars (91/441/EEC, 1991) (Hansen and Rosen, 1990; Ban-Weis et al., 2009; Dallmann et al., 2011; Wang et al., 2011, 2012), to passenger cars in use in the European Union today. These have smaller fuel consumption and thus emit less $\mathrm{CO}_{2}$. We compared the two methods in controlled conditions on a training track using different driving scenarios, to see how these real-world EFs are affected by vehicle speed, position of the measurement station and 
dynamics of the terrain. We further developed the two methods: the stationary method to improve detection of the plume beginning, and the chasing method to obtain the time evolution of the EF.

While measuring emissions of a vehicle by chasing it on a road, the dilution changes with vehicle shape, tailpipe position, the chasing distance, speed and changing of the chased vehicle exhaust flow (Chang et al., 2009; Vogt et al., 2003). To investigate the effect of these parameters during the determination of the EFs by chasing, and to further explain the results of the running integration calculation, we applied the chasing method to a vehicle equipped with portable emission measurement system (PEMS), which has shown to be well correlated with dynamometer measurements (Weiss et al., 2011).

\section{Experimental setup}

Experiments were conducted on two test circuits: the training track of the Slovenian national automobile and motorcycle association and the Italian Monza racing circuit. On the Slovenian track both chasing and stationary measurements (Sect. 2.1) were conducted on five in-use cars, while on the Italian circuit the chasing measurements were conducted on a vehicle that was equipped with PEMS (Sect. 2.2).

\subsection{Chasing vs. stationary measurements}

This part of the experiment was conducted on the training track of the Slovenian national automobile and motorcycle association on 23 December 2011. The track is a $1.3 \mathrm{~km}$ long circuit with two sharp turns and a slope (3\% grade). Along the track two measuring sites for the stationary method have been set up: one on the flat part of the road and one on the slope. In the stationary part of the experiment each car passed both stations in three different scenarios: with a constant speed of both 50 and $90 \mathrm{~km} \mathrm{~h}^{-1}$, and while accelerating from a stationary position about $10 \mathrm{~m}$ in front of the station. Each scenario was repeated five times. The second part of the experiment consisted of chasing a car with our mobile measuring station, making five laps on the training track circuit.

Both the chasing method (Wang et al., 2011) and the stationary method (Hansen and Rosen, 1990) were applied measuring the exhaust of five different passenger cars, properties of which are summarized in Table 1. Three cars had a compression ignition engine (diesel) and were compliant with Euro 3 emission standard (98/69/EC, 1998) with production years 2000, 2002 and 2004, and two cars were compliant with Euro 5 standard (715/2007/EC, 2007), of which one had a compression (diesel) and the other spark ignition engine (gasoline). The vehicles are henceforth referred to with abbreviations D3-00, D3-02, D3-04, D5-10 and G5-11. The classification of the abbreviations is as follows: D (G) denotes the vehicle was powered by diesel (gasoline) fuel, 3 (5) is the Euro 3 (Euro 5) standard to which the vehicle complied to and the last two numbers denote the car's production year. The Euro 3 cars were driven by their respective owners, the Euro 5 cars were driven by a professional driver who also drove the D3-02.

This part of the study was designed (a) to test the applicability and the reproducibility of the two measurement methods on personal vehicles (cars), (b) to see if EFs measured with the stationary technique would be higher or more repeatable on the slope where we would expect a more constant engine load, (c) to see the possible difference in EFs during stationary measurements having vehicles pass at two different speeds and while accelerating and (d) to compare the results of the two methods.

\subsection{Chasing vs. tailpipe measurements}

This part of the experiment was performed in Monza (Italy) on part of the Monza race track on 24 May 2012. The part of the track where we conducted measurements is flat and approximately $700 \mathrm{~m}$ long. In one chase the driver of the tested vehicle equipped with PEMS was instructed to steadily accelerate and shift up to the fourth gear, then reduce speed, make a sharp U-turn and return to the starting position at the end of which the mobile measurement station lagged behind the chased vehicle. This was repeated three times. The chased vehicle in this experiment was a Euro 3 (directive 2001/1/CE; see ref. 98/69/CE, 1998) diesel van equipped with PEMS. This experiment was set up so we could better understand the results of the chasing approach.

\subsection{Instrumentation}

Instruments used for stationary measurements on the flat part of the training track were the Dekati Electrical Low Pressure Impactor (ELPI+) for measuring PNs and number size distributions, an Aethalometer prototype AE33 (prototype ver. P10, made by Aerosol d.o.o.) for BC measurements, which was equipped with a cyclone inlet (aerodynamic diameter cutoff at $1.7 \mu \mathrm{m}$ ) to eliminate measuring re-suspended particles and a Vaisala flow-through Carbocap GMP343 for measuring $\mathrm{CO}_{2}$ concentrations. These instruments operated with 10,7 and $7 \mathrm{~L} \mathrm{~min}^{-1}$ flows, respectively. Sampling inlets were positioned next to the road about $10 \mathrm{~cm}$ from the ground.

Stationary measurements on the sloped part of the track and chasing measurements were performed with the mobile measurement platform, which was a small van equipped with a TSI Fast Mobility Particle Seizer (FMPS) for PN measurements and number size distributions, a second Aethalometer AE33 and another Carbocap GMP343. These instruments also operated with 10,7 and $7 \mathrm{~L} \mathrm{~min}^{-1}$ flows, respectively. The inlets of the mobile station were attached under the back door window on the right-hand side of the station. All equipment in the mobile station was powered by three 100 Ah batteries. 
Table 1. Tested vehicle summary (D3-00 stands for Diesel powered Euro 3 compliant, made in 2000; G5-11 stands for Gasoline powered Euro 5 compliant, made in 2011).

\begin{tabular}{|c|c|c|c|c|c|c|c|}
\hline Vehicle & $\begin{array}{l}\text { Fuel } \\
\text { type }\end{array}$ & $\begin{array}{l}\text { Engine } \\
\text { size (L) }\end{array}$ & $\begin{array}{r}\text { Max } \\
\text { engine } \\
\text { power } \\
(\mathrm{kW})\end{array}$ & $\begin{array}{l}\text { Year of } \\
\text { first } \\
\text { registration }\end{array}$ & $\begin{array}{r}\text { Approx. } \\
\text { kilometers } \\
\text { driven }\end{array}$ & $\begin{array}{l}\text { Compliant } \\
\text { Euro } \\
\text { standard }\end{array}$ & $\begin{array}{l}\text { After } \\
\text { treatment }\end{array}$ \\
\hline D3-00 & diesel & 1.9 & 85 & 2000 & 150000 & Euro 3 & catalytic reduction (cat) \\
\hline D3-02 & diesel & 1.9 & 81 & 2002 & 300000 & Euro 3 & cat \\
\hline D3-04 & diesel & 2.0 & 66 & 2005 & 75000 & Euro 3 & cat \\
\hline D5-10 & diesel & 2.2 & 110 & 2010 & 10000 & Euro 5 & cat + particle filter \\
\hline G5-11 & gasoline & 1.2 & 77 & 2011 & 10000 & Euro 5 & cat \\
\hline
\end{tabular}

All instruments were operated with $1 \mathrm{~s}$ time resolution with the exception of Carbocap GMP343 which needs $2 \mathrm{~s}$ to perform each measure.

All sampling lines were kept as short as possible (no longer than $2.5 \mathrm{~m}$ ). Isokinetic sampling was not attempted as it had a negligible effect on our measurements (Wang et al., 2011; Baron and Willeke, 2001).

As in the experimental protocol the PN was measured using two different measuring systems: the total PNs measured by ELPI+ and the FMPS were compared before the field activity. The instruments were running overnight measuring ambient concentrations. These showed good correlation $R^{2}=0.91$, but because the slope was 8.15 and the intercept -6630.9 we adjusted the ELPI+ data. After the adjustment was made, the responses of instruments on the test night were the same, and on the day of the training, track measurements the two showed similar background concentrations.

The data from the two aethalometers were compensated off-line for loading effects using the compensation algorithm also implemented online in the Aethalometer AE33 (Drinovec et al., 2014). After the compensation was applied, the data from the two aethalometers used in the training track experiment featured the regression slope 0.93 and intercept 0 , with $R^{2}=0.99$. The two $\mathrm{CO}_{2}$ probes also correlated well: $R^{2}=0.99$, slope 0.88 and intercept 0 .

In the Monza test the chased vehicle was equipped with a PEMS (Weiss et al., 2011), which consists of gaseous, exhaust gas analyzers $\left(\mathrm{CO}_{2}, \mathrm{CO}\right.$, THC and $\left.\mathrm{NO}_{\mathrm{x}}\right)$, an exhaust flow meter (EFM), a global positioning system (GPS) and a weather station. The mobile platform had an Aethalometer AE33 (ver. P20) equipped with a cyclone inlet (aerodynamic diameter cutoff at $1.7 \mu \mathrm{m}$ ) for the $\mathrm{BC}$ measurements, and flow-through Carbocap GMP343 sensor for the $\mathrm{CO}_{2}$ measurements, which was powered with one 100 Ah battery. The sampling line was again shorter than $2.5 \mathrm{~m}$; the inlet was mounted on the right-hand side external mirror.

\section{Emission factor calculations and data processing}

We calculated the EFs using the carbon balance method (Hansen and Rosen, 1990):

$\mathrm{EF}=\frac{\int_{i}^{j}\left(P_{j}-P_{i}\right) \mathrm{d} t}{\int_{i}^{j}\left(\mathrm{CO}_{2 j}-\mathrm{CO}_{2 i}\right) \mathrm{d} t} \cdot w_{\mathrm{c}}$,

where $w_{\mathrm{c}}$ represents the carbon fraction of fuel and was set to 0.861 for diesel and 0.864 for gasoline (Huss et al., 2013); $P$ in the equation represents the pollutant, either PN or BC in number of particles per $\mathrm{cm}^{3}$ and $\mathrm{ng}$ per $\mathrm{m}^{3}$, respectively; concentration of $\mathrm{CO}_{2}$ is in units of $\mathrm{mg} \mathrm{C} \mathrm{m}^{-3}$; and the subscripts $i$ and $j$ denote the time of the beginning and the end of the measured plume, respectively.

In stationary measurements, rapid concentration increases following each pass of the measured vehicle were measured. We included all peaks where the pollutant increase was higher than 3 standard deviations of the background concentrations. For each successful plume capture, the background concentrations were calculated as an average of $20 \mathrm{~s}$ before the inflection point. This point marked the beginning of the plume. The end of the plume was set to the time when the pollutant concentration time derivative reaches the minimum (Fig. 1). The data were smoothed with a $5 \mathrm{~s}$ running average and the time derivative calculated from three measurement points previous to the time of the calculated derivative. Our integrated peaks lasted around 10-20 s, similar to plume durations previously reported by Ban-Weis et al. (2009) and Dallmann et al. (2011). We determined the beginning and the end of the plume from $\mathrm{BC}$ measurements rather than from the $\mathrm{CO}_{2}$ peak (Ban-Weis et al., 2009). We found that performing the same integration analysis on all of the pollutants produced more consistent results. We noticed (similarly to Dallmann et al., 2011) that there was a difference in the response time of the instruments used.

During chasing measurements, dynamic time-resolved pollutant concentrations in the plume of the investigated vehicle were measured: an example measured during one lap 


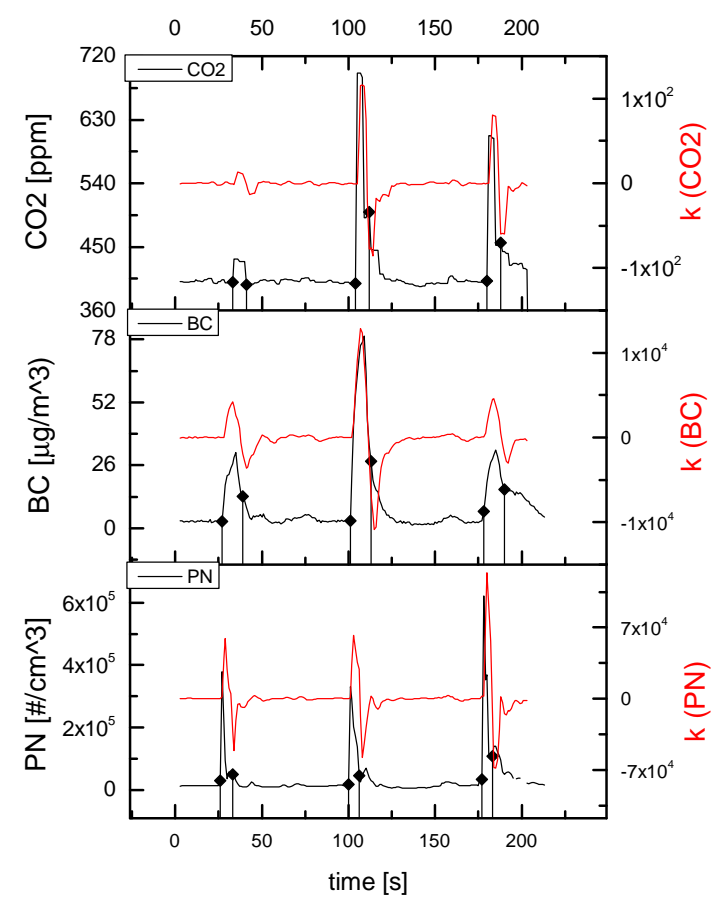

Figure 1. Examples of three consecutive stationary plume measurements. Marked with black dots and drop lines are the beginning and the end of each plume. The calculated slope $(k)$ of each pollutant which was used to determine the end of the plume is plotted in red.

on the Slovenian track is reported in Fig. 2. The EFs were calculated and compared using two approaches. In the first, we subtracted the background concentrations and then performed running integration with a $10 \mathrm{~s}$ time window to obtain a time-resolved EF. The second approach was bulk plume integration performed according to Wang et al. (2011), who integrated each measured pollutant from the beginning to the end of the chase.

For the chasing method it was most important to find the correct background for $\mathrm{CO}_{2}$, because the determination of the background influences the accuracy of the EF- as Wang et al. (2011) reported, changing the $\mathrm{CO}_{2}$ background for $2 \%$ changed the calculated EF for up to $40 \%$ (only up to $5 \%$ for changing BC or PN baseline). Thus, we analyzed the background and its influence on our calculations and, as reported in Sect. 4.2.2, we found a smaller variation of the EF due to the change of the $\mathrm{CO}_{2}$ background using the EF determination. For each car chase we subtracted the background which we set as a linear trend between the $20 \mathrm{~s}$ average of data we measured before and after the chase period when no car emissions were measured. The background did not change much in this period (Fig. 2), but we expect that during real-life onroad measurements, where spatial concentrations may vary more than they did in the controlled conditions of the training track, the background might change and hence the need for the linear approximation of the background during the chasing period. To describe the background variation we cal-

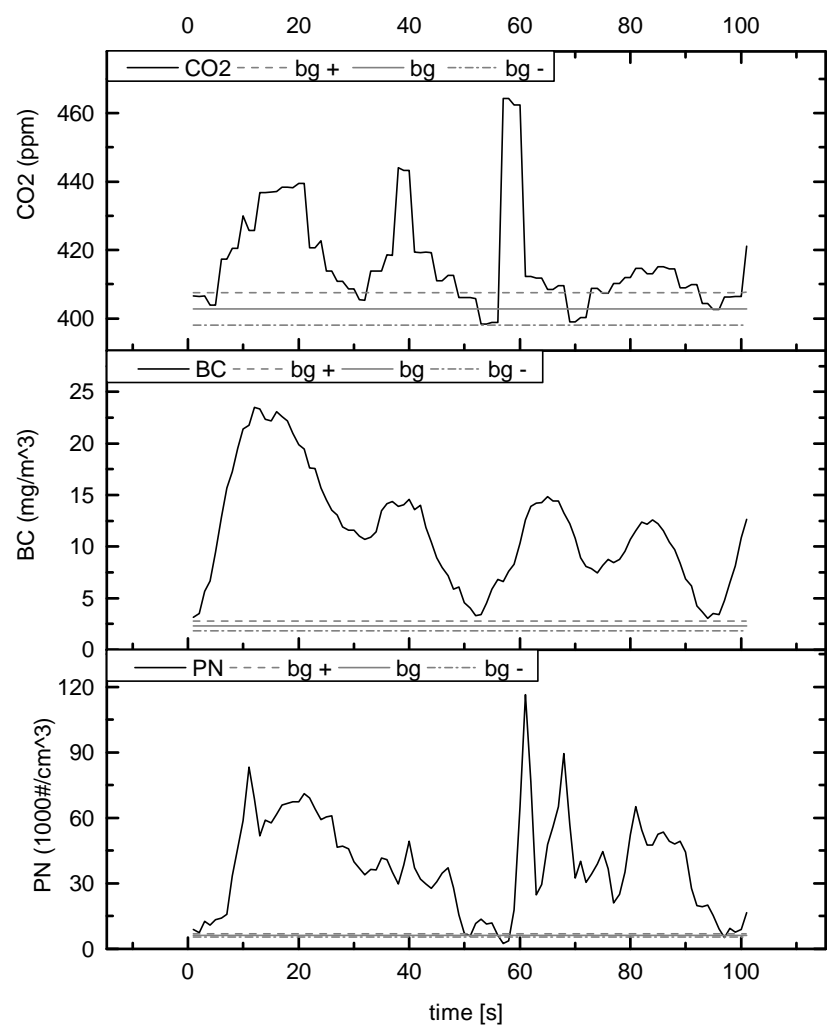

Figure 2. An example of chasing plume measurements (black solid line). Background (bg), background + and - and 2 standard deviations of background are shown in grey solid, dashed and dash-dotted line, respectively.

culated the standard deviation of the background from the measurements before the chase. In all, 2 standard deviations covered at least $90 \%$ of the variation. We added and subtracted 2 standard deviations from the background to determine the influence of background variation on the calculated EFs; results are discussed in Sect. 4.2.2.

\section{Results and discussion}

Results from the experimental campaign are reported and organized as follows: results from both the stationary and chasing methods are discussed in Sects. 4.1 and 4.2, respectively, while a comparison between the two approaches is reported in Sect. 4.3.

\subsection{Stationary measurements}

The first interest of this research was to see if this method was applicable on today's in-use cars that have smaller fuel consumption and therefore emit less $\mathrm{CO}_{2}$ than trucks, busses and pre-Euro cars, on which this method was so far used (e.g., Ban-Weis et al., 2009; Hansen and Rosen, 1990). To calculate an EF according to Eq. (1), we first need a valid measure- 
Table 2. Summarized emission factors (EFs) of individual vehicles for (a) black carbon (BC) and (b) particle number (PN).

\begin{tabular}{llrrrrr}
\hline (a) & EF BC $\left[\mathrm{g} \mathrm{kg}^{-1}\right]$ & D3-00 & D3-02 & D3-04 & D5-10 & G5-11 \\
\hline Average & 1.31 & 1.33 & 2.68 & $/$ & 0.09 \\
Median & 0.94 & 1.38 & 2.57 & 0.13 & 0.06 \\
Min & 0.24 & 0.61 & 0.81 & $/$ & 0.03 \\
Max & 4.82 & 2.30 & 6.49 & $/$ & 0.18 \\
& Count & 20 & 23 & 20 & 1 & 3 \\
\hline (b) & PN EF $\left[10^{15} \# \mathrm{~kg}^{-1}\right]$ & $\mathrm{D} 3-00$ & $\mathrm{D} 3-02$ & $\mathrm{D} 3-04$ & $\mathrm{D} 5-10$ & $\mathrm{G} 5-11$ \\
\hline & AVERAGE & 5.88 & 3.19 & 4.08 & 15.1 & 0.40 \\
& Median & 4.72 & 2.63 & 3.97 & 9.05 & 0.40 \\
Min & 1.19 & 1.25 & 1.83 & 8.21 & 0.17 \\
Max & 18.7 & 8.12 & 6.15 & 28.0 & 0.71 \\
Count & 24 & 27 & 22 & 3 & 12 \\
\hline
\end{tabular}

ment of $\mathrm{CO}_{2}$. The capture of increased $\mathrm{CO}_{2}$ concentrations in this experiment was high, and out of the 150 vehicle passes of the measurement stations we managed to measure 125 $\mathrm{CO}_{2}$ peaks. This meant we could detect fuel consumption of most vehicles passing the measuring site. We failed to detect the $\mathrm{CO}_{2}$ transient increase 13 times during $90 \mathrm{~km} \mathrm{~h}^{-1}$ passes and 12 times during $50 \mathrm{~km} \mathrm{~h}^{-1}$ passes of different vehicles. Considering results of the chasing experiment performed in Monza (see Sect. 4.2.3), we could attribute this to a probable combination of low-mass exhaust flow rate, high speed and consequently higher dilution rate.

To calculate an EF an increase of pollutant is also required, i.e., in this study either a BC or PN. Both Euro 5 vehicles had a small number of calculated EFs, due to the absence of BC and PN peaks. The few BC EFs of the Euro 5 vehicles that were measured were at least 10 times smaller than BC EFs of the Euro 3 vehicles. We could measure more PN EFs of the two Euro 5 vehicles (15 in total), of which D5-10 had the highest PN EF of all vehicles measured with stationary method, even though its total number of PN EFs was the smallest (we could calculate only three). The low values of the BC EFs for both Euro 5 vehicles indicate improved technology in lowering soot emissions. The infrequent high PN emissions may be due to nucleation of the exhaust vapors after being emitted in the ambient environment, which in the presence of soot nucleation would be suppressed (Kittelson, 1998).

In total, 88 and $67 \mathrm{PN}$ and $\mathrm{BC}$ EF, respectively, were calculated; during nine passes the Aethalometer advanced the tape and no BC measurements were taken. Table 2 summarizes EFs for individual cars in terms of average, median, minimum, maximum and the count of the obtained EFs.

The average values and the span of the three Euro 3 differed for both BC and PN EFs (Table 2). The highest BC emitter was D3-04, whose average EF was twice as high as D3-00, which had the lowest BC EF of the three Euro 3 cars. D3-04 also had the highest minimum and maximum BC EF of the three. The results are different for PN EF, where the highest emitter turned out to be D3-00. We will further ad-
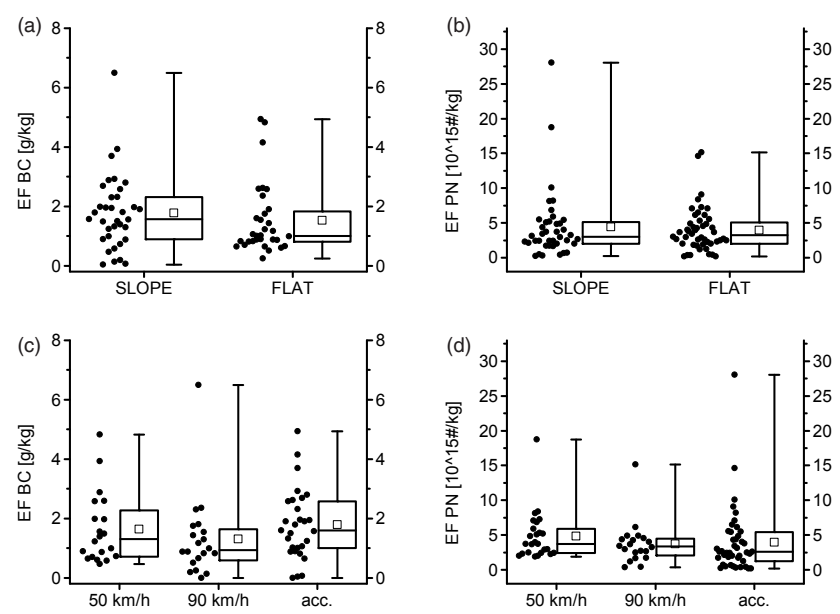

Figure 3. Stationary measurements of $\mathrm{BC}$ and $\mathrm{PN}$ emission factors for measurements performed on a slope and flat road (a and $\mathbf{b}$ ); and at different speeds of passing cars (c and $\mathbf{d})$. Values marked are the minimum and maximum (-), 25th and 75th percentile (lower and upper box lines), median (middle box line), and mean ( $\square$ ). Black dots represent the actual data points.

dress the differences in vehicles and also BC vs. PN EFs in comparison to the chasing method results in Sect. 4.3.2.

Position of the measuring station on a slope or flat road did not show significant changes in measured PN EFs, where the average on the slope was 4.41 and $3.97 \times 10^{15} \# \mathrm{~kg}^{-1}$ on the flat road (Fig. 3). The median did not change for PN EF (3.03 and $3.22 \times 10^{15} \# \mathrm{~kg}^{-1}$ on the slope and flat road measurements, respectively). The average of BC EFs measured on the slope was $1.78 \mathrm{~g} \mathrm{~kg}^{-1}$ and on flat road $1.52 \mathrm{~g} \mathrm{~kg}^{-1}$; the median $\mathrm{BC}$ EF values were higher $\left(1.56 \mathrm{~g} \mathrm{~kg}^{-1}\right)$ on slope as they were on the flat road $\left(1.01 \mathrm{~g} \mathrm{~kg}^{-1}\right)$. Both BC and PN EFs feature tails toward the larger EF values. We also notice that we were more successful in measurements on the flat road where we measured nine $\mathrm{CO}_{2}$ peaks more than on the slope. This could be due to the position of the inlets - on the flat part of the track they were closer to the exhaust pipes of the passing cars, whereas on the slope measurements the inlets were mounted on the side of the mobile station, further away from the exhaust.

Vehicle passes of the measuring site with different speed regimes produced similar spans for all vehicles for both PN and BC EFs (Fig. 3c and d). Median PN EF values were similar for 50 and $90 \mathrm{~km} \mathrm{~h}^{-1}$ passes, i.e., 3.74 and $3.34 \times 10^{15} \mathrm{~kg}^{-1}$, respectively, and slightly lower for the acceleration regime where the median was $2.60 \times 10^{15} \mathrm{~kg}^{-1}$. Median BC EFs were 1.30, 0.99 and $1.59 \mathrm{~g} \mathrm{~kg}^{-1}$ for driving regimes $50,90 \mathrm{~km} \mathrm{~h}^{-1}$ and accelerating, respectively; furthermore, the span of EFs was similar for all conditions.

These measurements show that a single stationary measurement is not necessarily the representative EF of that particular vehicle, and that we can produce similar fleet PNs 
Table 3. Summarized results of the chasing measurements. BC (a) and PN EF (b) are reported as the average, median, minimum and maximum of the running integration method and the result of bulk integration. In column headers EF, EF-, and EF+ denote the subtracted background used for the calculation of the EFs. For background influence analysis we first subtracted the linear fit of average background values measured before and after the chase (EF) then we tested it by subtracting (EF-) or adding (EF+) 2 standard deviations to the background value. The median EFs for each car are denoted in bold for clarity.

\begin{tabular}{|c|c|c|c|c|c|c|c|c|c|c|c|c|c|c|c|c|}
\hline \multirow[t]{2}{*}{ (a) } & \multirow{2}{*}{$\begin{array}{l}\mathrm{BC} \mathrm{EF} \\
{\left[\mathrm{g} \mathrm{kg}^{-1}\right]}\end{array}$} & \multicolumn{3}{|c|}{ D3-00 } & \multicolumn{3}{|c|}{ D3-02 } & \multicolumn{3}{|c|}{ D3-04 } & \multicolumn{3}{|c|}{ D5-10 } & \multicolumn{3}{|c|}{ G5-11 } \\
\hline & & $\mathrm{EF}-$ & $\mathbf{E F}$ & $\mathrm{EF}+$ & $\mathrm{EF}-$ & $\mathbf{E F}$ & $\mathrm{EF}+$ & $\mathrm{EF}-$ & EF & $\mathrm{EF}+$ & $\mathrm{EF}-$ & EF & $\mathrm{EF}+$ & $\mathrm{EF}-$ & $\mathbf{E F}$ & $\mathrm{EF}+$ \\
\hline \multirow[t]{4}{*}{ Running I. } & Average & 0.96 & 1.35 & 2.49 & 1.75 & 3.05 & 4.11 & 1.88 & 2.57 & 3.99 & 0.24 & 0.26 & 0.38 & 0.21 & 0.32 & 0.28 \\
\hline & Median & 0.89 & 1.13 & 1.48 & 1.56 & 2.22 & 3.02 & 1.90 & 2.48 & 3.23 & 0.18 & 0.17 & 0.14 & 0.14 & 0.13 & 0.09 \\
\hline & Min & 0.25 & 0.32 & 0.33 & 0.50 & 0.52 & 0.40 & 0.03 & 0.003 & 0.53 & 0.02 & 0.003 & 0.0001 & 0.01 & 0.0003 & 0.0003 \\
\hline & Max & 2.42 & 11.4 & 56.0 & 9.24 & 73.1 & 66.6 & 5.06 & 6.98 & 39.5 & 1.55 & 1.87 & 19.9 & 1.19 & 5.79 & 3.56 \\
\hline \multicolumn{2}{|c|}{ Bulk Int. } & 0.89 & 1.11 & 1.46 & 1.68 & 2.26 & 3.22 & 3.22 & 2.32 & 2.94 & 0.16 & 0.11 & 0.06 & 0.13 & 0.11 & 0.08 \\
\hline \multirow[t]{2}{*}{ (b) } & PN EF & \multicolumn{3}{|c|}{ D3-00 } & \multicolumn{3}{|c|}{ D3-02 } & \multicolumn{3}{|c|}{ D3-04 } & \multicolumn{3}{|c|}{ D5-10 } & \multicolumn{3}{|c|}{ G5-11 } \\
\hline & {$\left[10^{15} \mathrm{\# kg}^{-1}\right]$} & $\mathrm{EF}-$ & $\mathbf{E F}$ & $\mathrm{EF}+$ & $\mathrm{EF}-$ & EF & $\mathrm{EF}+$ & $\mathrm{EF}-$ & EF & $\mathrm{EF}+$ & $\mathrm{EF}-$ & EF & $\mathrm{EF}+$ & $\mathrm{EF}-$ & $\mathbf{E F}$ & $\mathrm{EF}+$ \\
\hline \multirow[t]{4}{*}{ Running I. } & Average & 3.68 & 5.35 & 10.1 & 6.66 & 26.2 & 12.2 & 5.23 & 7.39 & 11.6 & 2.95 & 3.77 & 6.24 & 0.56 & 0.95 & 1.24 \\
\hline & Median & 3.18 & 3.90 & 5.01 & 4.27 & 5.62 & 7.00 & 4.70 & 6.07 & 7.82 & 0.36 & 0.46 & 0.61 & 0.44 & 0.55 & 0.63 \\
\hline & Min & 0.31 & 0.78 & 0.90 & 0.17 & 1.76 & 2.39 & 0.002 & 0.0005 & 0.92 & 0.02 & 0.009 & 0.01 & 0.06 & 0.06 & 0.08 \\
\hline & Max & 16.1 & 65.3 & 229 & 107 & 2371 & 167 & 16.3 & 32.5 & 156 & 77.0 & 100 & 144 & 3.63 & 10.8 & 16.2 \\
\hline \multicolumn{2}{|c|}{ Bulk Int. } & 3.15 & 4.07 & 5.52 & 4.76 & 6.59 & 9.67 & 4.70 & 5.85 & 7.53 & 2.53 & 3.04 & 3.80 & 0.45 & 0.55 & 0.71 \\
\hline
\end{tabular}

and BC EF distributions, regardless of the speed regime or slope on which the measurement station would be positioned. This suggests that a large number of measurements should be taken to describe a representative fleet (like in Carslaw and Rhys-Tyler, 2013, for gaseous emissions), which should be possible using the stationary method.

In this respect, to assess the reliability and applicability of the stationary method, a comparison with the chasing method was done and it is reported in Sect. 4.3. Moreover, the same chasing method was in turn validated through PEMS measurements (Sect. 4.2.3).

\subsection{Chasing measurements}

\subsubsection{Chasing emission factors}

Chasing results are summarized for each car in Table 3 where we report the average, median, minimum and maximum of the 10 s running integration technique, and the bulk EFs calculated as an integral of the entire 5-6 min chasing run. In the same table we also report the influence of the determined background on the calculated $\mathrm{EF}$, which we will elaborate on further in Sect. 4.2.2. We obtained almost the same values in bulk integration and median of the running integration for all vehicles (Table 3, EF columns for each car). This shows consistency between the two data processing methods, with the running integration providing the time evolution of the EF.

Because we omitted parts of data when values fell below the set background, the analysis turned out to be more difficult for the two Euro 5 vehicles. In these two cases we had not only a low signal-to-noise ratio for the $\mathrm{CO}_{2}$ but also low signals of BC and PN. D5-10 again had a single super emission peak of PN which lasted for almost the entire first lap of the chase; thus, the PN EF running integration maximum is high $\left(100 \times 10^{15} \# \mathrm{~kg}^{-1}\right)$. G5-11 emitted elevated particle concentrations throughout the chase but there was very little emitted BC. The calculated medians of both BC and PN EFs are low for the two technically advanced vehicles, about an order of magnitude smaller than median EFs of Euro 3 vehicles.

In a different approach, Herndon et al. (2005) calculated the emission ratio in a chasing campaign from a regression line between the measured species and $\mathrm{CO}_{2}$, assuming that $3160 \mathrm{~g}$ of $\mathrm{CO}_{2}$ is produced from $1 \mathrm{~kg}$ of fuel burned, which roughly translates to $w_{\mathrm{c}}=0.85$ fraction of carbon in fuel. This works well if spans of both the pollutant and $\mathrm{CO}_{2}$ are large: Herndon et al. (2005) report a $\mathrm{CO}_{2}$ span of $50 \mathrm{ppm}$ and $\mathrm{NO}_{\mathrm{x}}$ span of $500 \mathrm{ppb}$. In Shorter et al. (2005) the span of $\mathrm{CO}_{2}$ is from 400 to $2000 \mathrm{ppm}$, for NO from 0 to $15000 \mathrm{ppb}$, and for $\mathrm{NO}_{2}$ from 0 to $150 \mathrm{ppb}$. In our case the measured spans were lower than both these examples, especially for the two Euro 5 vehicles and calculating a regression line is thus not applicable.

\subsubsection{Influence of background determination}

To analyze the sensitivity of EFs to the determination of the background, we calculated the EFs with three different background levels. First the background was set by calculating the linear trend between the $20 \mathrm{~s}$ average before and after the chase. Background variability was described with 2 standard deviations of the $20 \mathrm{~s}$ data before the chase, which covered at least $90 \%$ of background variability. This value was then added to/subtracted from the background linear trend. In Table 3 the EFs calculated from background with 2 standard deviations added or subtracted are marked with $\mathrm{EF}+$ and $\mathrm{EF}-$, respectively. Median values of $\mathrm{BC}$ EFs are again very consistent with the bulk integration values using the same background. The background changes affected both the median 
of the time-resolved measurements and the bulk integration result, for about $-24 /+26 \%$. The changes had a bigger influence on the maximum EF values. PN EF did not match as well for the EF+ median but other than that the results were again similar for bulk and median of the running integration. Again we had tails of super emission, here even more pronounced than for BC EF.

The advantage of the running integration method is that with it we can obtain an $\mathrm{EF}$ distribution. In both $\mathrm{BC}$ and PN EFs the distributions are best described with the median value, which has shown to be most characteristic for the vehicle; however, the seldom high emission peaks should not be completely overlooked as their contribution to total emissions could be large. Our method may have difficulties in precisely determining the maximum value of the $\mathrm{EF}$ in the super emission tail, which can also depend on a specific engine operation state that could or could not have been reproduced in the five lap chase.

\subsubsection{Influence of dilution on chasing $\mathrm{CO}_{2}$ measurements}

The chasing method was further evaluated using tailpipe measurements of $\mathrm{CO}_{2}$ by PEMS. In this test we wanted to see how mobile measurements match direct in-exhaust measurements of the chased vehicle emissions. From these measurements we calculated the dilution rate (DR) as a ratio of the $\mathrm{CO}_{2}$ measured by PEMS and by the chasing instrument (Chang et al., 2009) results are presented in Fig. 4. Our calculated DR values range from about 100, when we were in closer proximity of the chased vehicle and the speed of both vehicles was smaller, to the maximum value of about 72000 when both emitted $\mathrm{CO}_{2}$ and the exhaust mass flow rate drop. This occurred at the end of the track where we had to slow down to make a sharp U-turn. Excluding this period the maximum DR value was 8943 and the median 1077. This is similar to the measurements of Vogt et al. (2003), where they reported dilution factors, measured at an approximately constant 14,50 and $100 \mathrm{~m}$ distance from a diesel car going 50$100 \mathrm{~km} \mathrm{~h}^{-1}$, ranging from 926 to 9300 .

The dilution does not affect the calculated $\mathrm{BC} \mathrm{EF}$, as we can see from Fig. 4. The BC EF is the highest just before the highest cruising speed is reached; the dilution ratio is the highest when the exhaust mass flow rate drops. This is consistent with the findings of Chang et al. (2009), who reported that the dilution ratio depends not only on speed but also on exhaust flow rate and other parameters that are more important in near-wake region. Omitted parts when $\mathrm{CO}_{2}$ drops below the background overlap with parts when there is little to no $\mathrm{CO}_{2}$ emitted from the exhaust pipe; thus, the measured concentrations do not reach above the background level.

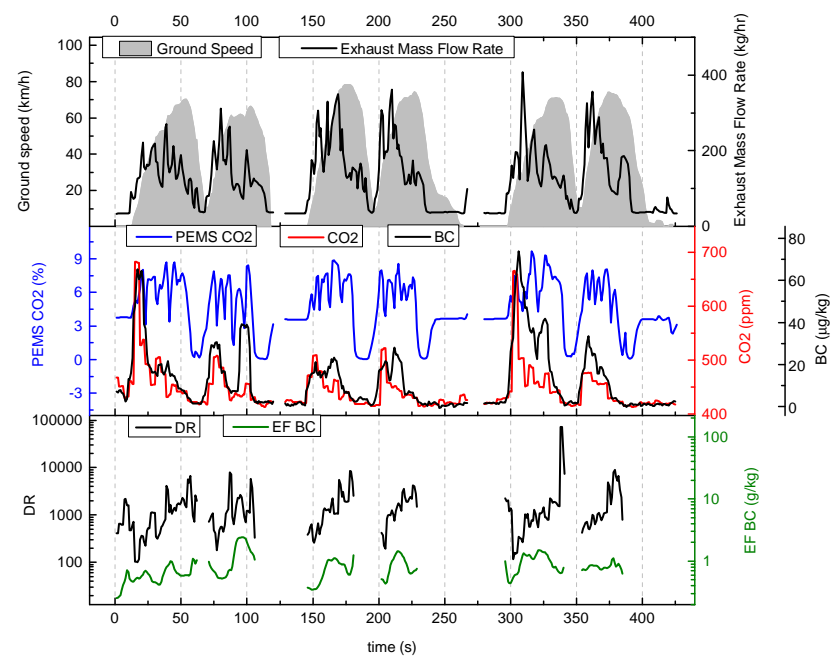

Figure 4. Tailpipe measurements performed with portable emission measurement system (PEMS) are ground speed (shaded grey) and exhaust mass flow rate (black) - top; and $\mathrm{CO}_{2}$ (blue) - middle. Also in the middle plot are $\mathrm{CO}_{2}$ and $\mathrm{BC}$ measured with mobile station in red and blue, respectively. Calculated dilution ratio (DR) in black and $\mathrm{BC}$ EF in green - bottom. BC EF does not show any significant dependence on DR. Note the log scales for DR and EF.

\subsection{Comparing emission factors determined with different methods}

\subsubsection{Stationary and chasing emission factors}

Another objective of this study was to compare the results of the chasing and the stationary methods. We plotted together the EFs of both methods for individual vehicles in Fig. 5 because the median values of the chasing method overlapped so well with the bulk integration, we omitted the latter from the plot. Figure 5 shows box plots for each car D3-00, D3-02, D3-04, D5-10 and G5-11; letters C and S mark the chasing and stationary method, respectively. Grey dots represent the actual data points: there is a big difference in the measurement counts for both methods, i.e., chasing method consists of about 600 points, and the stationary measurements feature only about 20 for Euro 3 vehicles and a very scarce number of EFs for the two Euro 5 vehicles.

We can see very good agreement between the BC EF of D3-00 and D3-04, due to not only the median values that are very close but also the tails of both methods match (see also Tables 2 and 3). Here we can also see that the tails of the chasing method have only a few points that are high enough to skew the distributions this is even more pronounced with PN EFs. The D3-02 stationary EFs are systematically lower than the chasing results. We believe this was because the D302 driver was a professional driver who could produce the most repeatable stationary results, whereas for the chasing measurement we could capture the whole emission range of the vehicle. For real-world measurements we would not ex- 

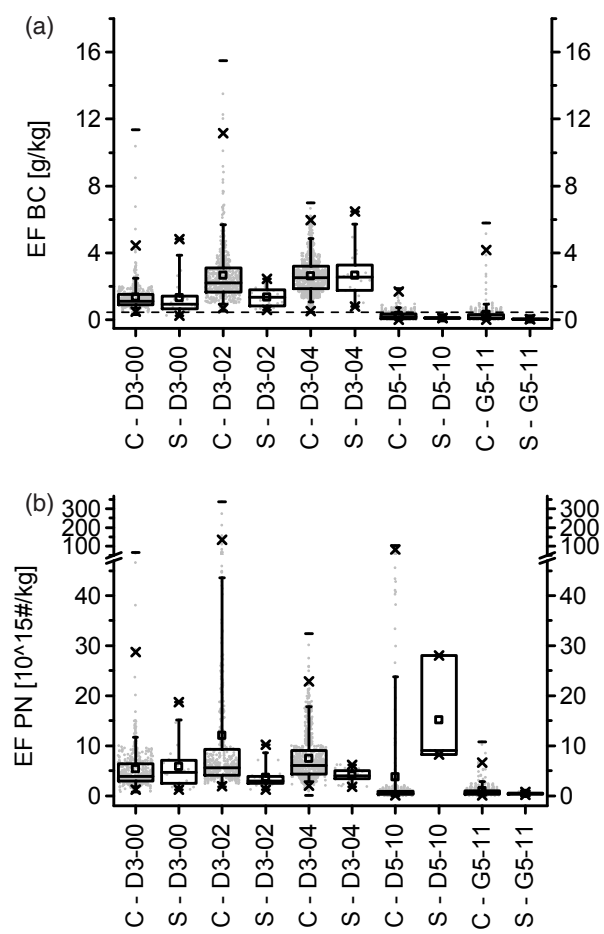

Figure 5. Black carbon (a) and particle number emission factor distributions (b) for each car measured with chasing (C) and stationary (S) method. Marked values represented are the minimum and maximum (-), 1st and 99th percentile (x), 5th and 95th percentile (whiskers), 25th and 75th percentile (bottom and upper box lines), median (middle box line) and mean ( $\square$ ). Grey dots represent the actual data points. The Euro 3 emission standard recalculated from particle mass to $\mathrm{BC}$, assuming consumption of $6 \mathrm{~L}(100 \mathrm{~km})^{-1}$ and $48 \%$ BC content in PM is shown with dashed line in (a).

pect the professional driver's driving to be representative, as most drivers are not professionals. Also a larger number of stationary measurements may show a distribution closer to the chasing measurements. PN EFs of the two methods match well only for the D3-00; the other two vehicles PN EFs were much higher compared with the chasing method than those measured with the stationary method.

Comparing the EFs determined in this study to those in previous studies, we see that PN EFs and BC EFs determined here are similar to the arithmetic mean PN $\left(4.7 \times 10^{15} \# \mathrm{~kg}^{-1}\right)$ and $\mathrm{BC}\left(1.7 \mathrm{~g} \mathrm{~kg}^{-1}\right) \mathrm{EFs}$ of Ban-Weiss et al. (2009). Hudda et al. (2013) reported lower median PN EFs for light-duty gasoline vehicles $\left(0.43 \times 10^{15} \mathrm{\#} \mathrm{kg}^{-1}\right)$ and similar values for heavy-duty diesel vehicles $(4.2$ or $\left.5.2 \times 10^{15} \mathrm{\#} \mathrm{kg}^{-1}\right)$. The BC EF $\left(0.07 \mathrm{~g} \mathrm{~kg}^{-1}\right)$ from these previous studies for light-duty gasoline vehicles is similar to our stationary measurement median of the gasoline car, but lower than the chasing median. The heavy-duty diesel BC EFs $\left(0.41\right.$ and $\left.1.33 \mathrm{~g} \mathrm{~kg}^{-1}\right)$ from these previous studies resemble our D3-00 cars' median and minimum; at the same time the values from previous studies lie at about the half of

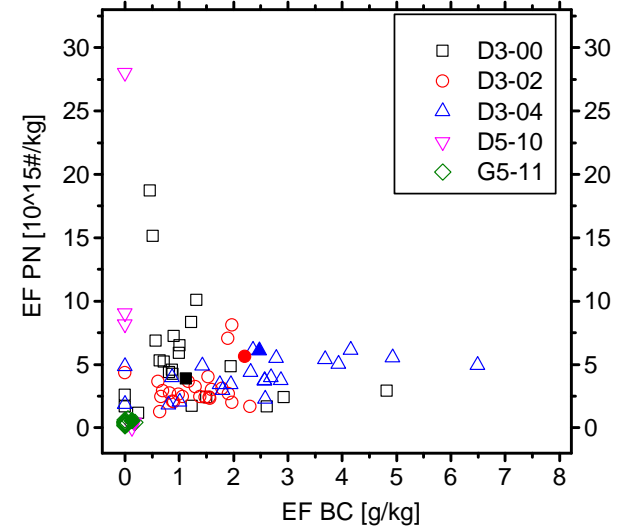

Figure 6. Particle number emission factors (PN EF) versus black carbon emission factors (BC EF) measured at the same vehicle drive-by. Empty symbols represent measurements with the stationary method; full shapes denote the median of EFs measured with the chasing method. G5-11 and D5-10 overlap and thus the latter is not visible.

the medians of the other two Euro 3 cars we measured. BC EFs similar to those of Hudda et al. (2013) were previously reported by Wang et al. (2012) for their truck fleet (1.1 and $0.4 \mathrm{~g} \mathrm{~kg}^{-1}$ for trucks registered in Chongqing and Beijing, respectively, the latter being subdue to more strict regulation of fuel quality), and by Dallmann et al. (2011), who also observed a decrease in average BC EFs (1.07 and $0.49 \mathrm{~g} \mathrm{~kg}^{-1}$ ) on their measured truck fleet after a more stringent emission legislation was enforced at the Port of Oakland, California, USA.

\subsubsection{Particle number and black carbon emission factors}

Comparing $\mathrm{PN} \mathrm{EF}$ and $\mathrm{BC} \mathrm{EF}$ that were calculated from the same vehicle drive-by (Fig. 6), we see that the highest PN $\mathrm{EF}$ and the highest $\mathrm{BC} \mathrm{EF}$ do not coincide. This was also observed by Ban-Weis et al. (2009) on their 300-vehicle fleet. In our study, D5-10 produced the highest stationary PN EF, D3-04 the highest BC EF, D3-02 stationary EFs lie between these two and D3-00 features both a high PN EF and $\mathrm{BC}$ EF, occurring at different vehicle passes. This is inline with the theory that the soot particles inhibit formation of nucleation particles in the exhaust (Kittelson, 1998). The median of chasing EFs calculated with running the integration method is also marked in Fig. 6 for comparison; they all match well with the stationary measurements.

To further explain the difference between $\mathrm{PN}$ and $\mathrm{BC} \mathrm{EF}$ behavior, we segregated the PN EF into three size bins and calculated their individual EFs, using the running integration approach. Besides the total PN EF we now calculate the PN $\mathrm{EF}$ for three aerodynamic particle diameter segments: less than 50,50 to $200 \mathrm{~nm}$ and larger than $200 \mathrm{~nm}$. We can see from Fig. 7 that the PN EF from the 50 to $200 \mathrm{~nm}$ range coin- 


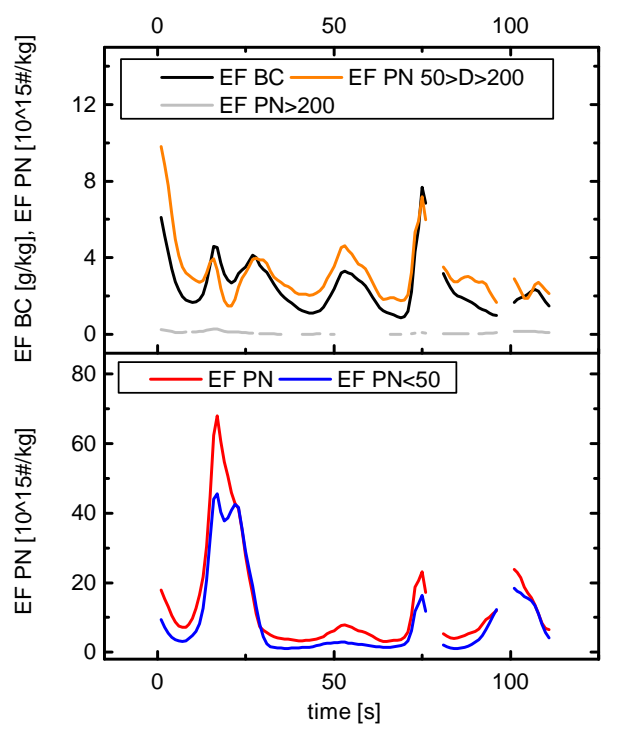

Figure 7. A sample of chasing emission factors for black carbon (BC) and particle number (PN) for different size fractions for D302: BC (black), total PN (red), PN of particles smaller than $50 \mathrm{~nm}$ (blue), PN of particles from 50 to $200 \mathrm{~nm}$ (orange) and PN of particles larger than $200 \mathrm{~nm}$ (grey).

cides well with the BC EF. The PN EF from the 50 to $200 \mathrm{~nm}$ range is in this case very small compared to the EF of particles smaller than $50 \mathrm{~nm}$. These dominated in parts of the D3-02 plume, e.g., one lap example of this vehicle in Fig. 7. We found similar super emissions of particles smaller than $50 \mathrm{~nm}$ in the D5-10 plume. We can see in Fig. 7 that from 30 to 70 s total PN EFs followed BC EFs; these findings are consistent and complementary to our stationary observations in Fig. 6, where PN EFs and BC EFs did not overlap because the constituents of the exhaust changed with driving dynamics; similar results were reported in Sharma et al. (2005).

\subsubsection{Black carbon emission factors measured in real driving conditions, emission standards and laboratory measurements}

We wanted to know if our Euro 3 vehicles are still compliant with their legislative standard and how our real-world driving approximation matches the legislative one; therefore, we recalculated the Euro 3 emission standard from PM in [ $\left.\mathrm{g} \mathrm{km}^{-1}\right]$ to a BC EF in $\left[\mathrm{g} \mathrm{kg}^{-1}\right]$, assuming there is $47.6 \%$ of elemental carbon (which we equate with $\mathrm{BC}$ in this particular campaign) in emitted diesel particulate mass (Landis et al., 2007, similar in Sharma et al., 2005), fuel density at $0.832 \mathrm{~kg} \mathrm{~L}^{-1}$ (mean of limit values of EN ISO 3675 and EN ISO 12185) and fuel consumption of 6 or $8 \mathrm{~L}(100 \mathrm{~km})^{-1}$. Car owners of the three Euro 3 cars reported that their cars consume 7-9, 5-6 and around $8 \mathrm{~L}(100 \mathrm{~km})^{-1}$ for D3-00, D302 and D3-04, respectively. We did not use the lower limits as they applied for highway driving, which was not the case in our experiment. By the recalculation, a Euro 3 compliant car with 6 or $8 \mathrm{~L}(100 \mathrm{~km})^{-1}$ fuel consumption could emit 0.48 or $0.36 \mathrm{~g} \mathrm{BC}$ per $\mathrm{kg}$ fuel; therefore, we marked the limit line of $6 \mathrm{~L}(100 \mathrm{~km})^{-1}$ consumption in Fig. 5a. From these calculations the median BC EF determined by stationary measurements of all Euro 3 cars is not expected to be compliant with legislation, nor is the median chasing BC EF. The most probable cause of difference is the difference between the driving regime used here and the one in emission standard testing. In our case we had a track with slope and curves, while in the European emission standards the new European driving cycle is used where the changes in speed are gradual. Future emission standards should also address these super emission peaks, which may substantially contribute to total emissions.

BC EFs for a Euro 5 gasoline and a Euro 3 diesel car were recently measured in laboratory experiments by Platt et al. (2013) and Chirico et al. (2010). Platt et al. (2013) measured emissions of a single gasoline Euro 5 vehicle on a dynamometer using the new European driving cycle and report a BC EF of $0.02 \mathrm{~g} \mathrm{~kg}^{-1}$. Chirico et al. (2010) measured BC EFs of three in-use cars with different aftertreatment devices. Most of their presented measurements are performed with the engine in idle mode, where $\mathrm{BC}$ EFs range from 0.466 to $0.763 \mathrm{~g} \mathrm{~kg}^{-1}$ fuel; one car was also measured at the speed of $60 \mathrm{~km} \mathrm{~h}^{-1}$ with a reported BC EF of $0.512 \mathrm{~g} \mathrm{~kg}^{-1}$. These numbers are lower than the median $\mathrm{EF}$ values determined in our on-road measurements but still within the measurement range reported here (see Tables 2 and 3).

\section{Conclusions}

Measuring vehicle EFs in real driving condition can bring further understanding of the actual fleet emissions. It can be a cost-effective way to monitor fleet emissions by measuring a large number of vehicles and to check if measures taken to reduce emissions were effective. We further developed two such methods and tested them in a controlled environment. We measured EFs of two parameters: the particle number concentration (PN) and black carbon (BC), both being recognized as closely related to deleterious health effects of particulate air pollution than the currently used legislative particle trait - their mass (PM) (e.g., Janssen et al., 2011; Vinzents et al., 2005, and references therein).

We have shown that the stationary and the chasing methods yield similar EFs and can thus be complementary. Both showed that a single stationary measurement of one vehicle, or the bulk EF of one chase, may not be representative of the vehicles EF span. Both methods showed how the emissions of a single vehicle changed with the driving conditions and further indicated that using a single number as a representation of that vehicle EF might not be appropriate; rather the distribution of that vehicles EF should be considered, where a single vehicle EF distribution has the most consistent number of measurements around the median value and 
is accompanied by a tail of super emissions. These emission peaks may be similar to what Ajtay et al. (2005) found in their dynamometer study; and to $\mathrm{NO}_{\mathrm{x}}$ emissions of different driving cycles reported in the Franco et al. (2013) review of EF development. We found vehicle-specific EF distribution for each of the investigated cars. In the stationary measurements D3-00 and D3-02 have similar average BC EF, but their distributions are different - D3-00 median is lower and tail longer than D3-02. We found that measuring at different speeds or on different slope does not increase the EF (similarly to Ban-Weis et al., 2009). Measuring during acceleration and in close proximity of the exhaust pipe improves the measurement collection efficiency. This knowledge on EF distributions could be beneficial, if included in models of traffic emissions.

With tailpipe measurements, we calculated the dilution ratio of $\mathrm{CO}_{2}$ in the plume of the chased vehicle between the exhaust and the mobile measurement station. We found that the EF does not change with the dilution ratio; it is however sensitive to low exhaust $\mathrm{CO}_{2}$ concentrations of the chased vehicle. If there is no $\mathrm{CO}_{2}$ emitted from the chased vehicle, none can be measured and thus such parts should be omitted from the results.

The cost of both methods is low and each has its pros and cons - stationary needs more measurements of a single vehicle to obtain the representative $\mathrm{EF}$ distribution or a measurement of a large number of vehicles to obtain a representative distribution for the fleet, but is not affected by the background as much as the chasing method. With the latter we can get the EF distribution in a single chase, but the data are more difficult to collect and analyze due to possible disturbances from other vehicles on the road or sources close to the road, which may disturb the background. However, both are a valuable contribution to understanding fleet emissions as they can be used to measure the versatility of the in-use fleet. Using distributions of measured real-world EFs may improve modeling of traffic emissions. This may be especially true for $\mathrm{BC}$, since it is not as affected by environmental conditions as PN or particle mass. In disperse and variable air pollution source like traffic, it is advantageous to have different approaches and insights to the problem. By comparing results of different measurements like dynamometer and real-world measurements, we can understand traffic emissions better. The methodology described herein will be used to compile the EF inventory of the European in-use car fleet, measured in real driving conditions in winter on Slovenian roads.

Acknowledgements. This research was partly funded by the European Social Fund (SPIRIT, contract no. P-MR-10/04). I. Ježek, L. Drinovec and G. Močnik are employed by Aerosol d.o.o., where the Aethalometer AE33 was developed and is being manufactured. The authors would like to thank TSI and Dekati for lending us their instruments, Slovenian national automobile and motorcycle association for letting us use their track and lending us a vehicle, and Autodromo nazionale Monza for letting us use their track. Thanks Anže Buh, Polona Ježek, Helena Ježek and Toyota center Ljubljana for lending us their vehicles. Many thanks to Tomaž Katrašnik and André S. H. Prévôt for helpful debates and to our colleagues at Aerosol for their technical support.

Edited by: M. Sipilä

\section{References}

91/441/EEC: Council directive of 26 June 1991 amending Directive $70 / 220 / \mathrm{EEC}$ on the approximation of the laws of the Member States relating to measures to be taken against air pollution by emissions from motor vehicles, 1991.

98/69/EC: Directive of the European parliament and of the council relating to measures to be taken against air pollution by emissions from motor vehicles and amending Council directive 70/220/EEC, 13 October 1998.

715/2007/EC: Regulation (EC) No 715/2007 of the European parliament and of the council, on type approval of motor vehicles with respect to emissions from light passenger and commercial vehicles (Euro 5 and Euro 6) and on access to vehicle repair and maintenance information, 20 June 2007.

2008/50/EC: Directive of the European parliament and of the council on ambient air quality and cleaner air for Europe, 21 May 2008.

Ajtay, D., Weilenmann, M., and Soltic, P.: Towards accurate instantaneous emission models, Atmos. Environ., 39, 2443-2449, doi:10.1016/j.atmosenv.2004.03.080, 2005.

Ban-Weiss, G. A., Lunden, M. M., Kirchstetter, T. W., and Harley, R. A.: Measurement of black carbon and particle number emission factors from individual heavy-duty trucks, Environ. Sci. Technol., 43, 1419-1424, 2009.

Baron, P. A. and Willeke, K.: Aerosol Measurement \& Principles, Techniques, and Applications, 2nd Edn., John Wiley \& Sons, New York, 2001.

Bishop, G. A., Stedman, D. H., and Ashbaugh, L.: Motor vehicle emissions variability, J. Air Waste Manage., 46, 667-675, 1996.

Bond, T. C., Doherty, S. J., Fahey, D. W., Forster, P. M., Berntsen, T., DeAngelo, B. J., Flanner, M. G., Ghan, S., Kärcher, B., Koch, D., Kinne, S., Kondo, Y., Quinn, P. K., Sarofim, M. C., Schultz, M. G., Schulz, M., Venkataraman, C., Zhang, H., Zhang, S., Bellouin, N., Guttikunda, S. K., Hopke, P. K., Jacobson, M. Z., Kaiser, J. W., Klimont, Z., Lohmann, U., Schwarz, J. P., Shindell, D., Storelvmo, T., Warren, S. G., and Zender, C. S.: Bounding the role of black carbon in the climate system: A scientific assessment, J. Geophys. Res.-Atmos., 118, 5380-5552, doi:10.1002/jgrd.50171, 2013.

Carslaw, D. C. and and Rhys-Tyler, G.: "New insights from comprehensive on-road measurements of $\mathrm{NO}_{\mathrm{x}}, \mathrm{NO}_{2}$ and $\mathrm{NH}_{3}$ from vehicle emission remote sensing in London, UK", Atmos. Environ., 81, 339-347, doi:10.1016/j.atmosenv.2013.09.026, 2013.

Chang, V. W., Hildemann, L. M., and Chang, C. H.: Dilution rates for tailpipe emissions: effects of vehicle shape, tailpipe position, and exhaust velocity, J. Air Waste Manage, 59, 715-724, 2009.

Chirico, R., DeCarlo, P. F., Heringa, M. F., Tritscher, T., Richter, R., Prévôt, A. S. H., Dommen, J., Weingartner, E., Wehrle, G., Gysel, M., Laborde, M., and Baltensperger, U.: Impact of af- 
tertreatment devices on primary emissions and secondary organic aerosol formation potential from in-use diesel vehicles: results from smog chamber experiments, Atmos. Chem. Phys., 10, 11545-11563, doi:10.5194/acp-10-11545-2010, 2010.

Dallmann, T. R., Harley, R. A., and Kirchstetter, T. W.: Effects of diesel particle filter retrofits and accelerated fleet turnover on drayage truck emissions at the Port of Oakland, Environ. Sci. Technol., 45, 10773-10779, doi:10.1021/es202609q, 2011.

De Haan, P. and Keller, M.: Modelling fuel consumption and pollutant emissions based on real-world driving patterns: the HBEFA approach, Int. J. Environ. Pollut., 22, 240-258, 2004.

Drinovec, L., Močnik, G., Zotter, P., Prévôt, A. S. H., Ruckstuhl, C., Coz, E., Rupakheti, M., Sciare, J., Müller, T., Wiedensohler, A., and Hansen, A. D. A.: The "dual-spot" Aethalometer: an improved measurement of aerosol black carbon with real-time loading compensation, Atmos. Meas. Tech. Discuss., 7, 1017910220, doi:10.5194/amtd-7-10179-2014, 2014.

Ferrero, L., Castelli, M., Ferrini, B. S., Moscatelli, M., Perrone, M. G., Sangiorgi, G., D’Angelo, L., Rovelli, G., Moroni, B., Scardazza, F., Močnik, G., Bolzacchini, E., Petitta, M., and Cappelletti, D.: Impact of black carbon aerosol over Italian basin valleys: high-resolution measurements along vertical profiles, radiative forcing and heating rate, Atmos. Chem. Phys., 14, 96419664, doi:10.5194/acp-14-9641-2014, 2014.

Franco, V., Kousoulidou, M., Muntean, M., Ntziachristos, L., Hausberger, S., and Dilara, P.: Road vehicle emission factors development: A review, Atmos. Environ., 70, 84-97, doi:10.1016/j.atmosenv.2013.01.006, 2013.

Hansen, A. D. A. and Rosen, H.: Individual measurements of the emission factor of aerosol black carbon in automobile plumes, J. Air Waste Manage., 40, 1654-1657, 1990.

Herndon, S. C., Shorter, J. H., Zahniser, M. S., Wormhoudt, J., Nelson, D. D., Demerjian, K. L., and Kolb, C. E.: Real-time measurements of $\mathrm{SO}_{2}, \mathrm{H}_{2} \mathrm{CO}$, and $\mathrm{CH}_{4}$ emissions from in-use curbside passenger buses in NewYork City using a chase vehicle, Environ. Sci. Technol., 39, 7984-7990, 2005.

Hudda, N., Fruin, S., Delfino, R. J., and Sioutas, C.: Efficient determination of vehicle emission factors by fuel use category using on-road measurements: downward trends on Los Angeles freight corridor I-710, Atmos. Chem. Phys., 13, 347-357, doi:10.5194/acp-13-347-2013, 2013.

Huss, A., Maas, H., and Hass, H.: Tank-to-weels Report version 4, Publications Office of the European Union; ISBN 978-92-7931195-6 (pdf), 2013.

Janssen, N. A. H., Hoek, G., Simic-Lawson, M., Fischer, P., van Bree, L., ten Brink, H., Keuken, M., Atkinson, R. W., Ross Anderson, H., Brunekreef, B., and Cassee, F. R.: Black Carbon as an Additional Indicator of the Adverse Health Effects of Airborne Particles Compared with $\mathrm{PM}_{10}$ and $\mathrm{PM}_{2.5}$, Environ Health Persp., 119, 1691-1699, doi:10.1289/ehp.1003369, 2011.

Kittelson, D. B.: Engines and nano particles: a review, J. Aerosol Sci., 29, 575-588, 1998.

Kuhns, H. D., Mazzoleni, C., Moosmüller, H., Nikolic, D., Keislar, R. E., Barber, P. W., Zheng Li, Etyemezian, V., and Watson, J. G.: Remote sensing of PM, NO, CO and $\mathrm{HC}$ emission factors for on-road gasoline and diesel engine vehicles in Las Vegas, NV, Sci. Total Environ., 322, 123-137, 2004.

Landis, M. S, Lewis, C. W., Stevens, R. K., Keeler, G. J, Dvonch, J. T., and Tremblay, R. T.: Ft. McHenry tunnel study: Source profiles and mercury emissions from diesel and gasoline powered vehicles, Atmos. Environ., 41, 8711-8724, doi:10.1016/j.atmosenv.2007.07.028, 2007.

Moroni, B., Cappelletti, D., Marmottini, F., Scardazza, F., Ferrero, L., and Bolzacchini, E.: Integrated single particle-bulk chemical approach for the characterization of local and long range sources of particulate pollutants, Atmos. Environ., 50, 267-277, doi:10.1016/j.atmosenv.2011.12.022, 2012.

Ntziachristos, L. and Samaras, Z.: Speed-dependent representative emission factors for catalyst passenger cars and influencing parameters, Atmos. Environ., 34, 4611-4619, doi:10.1016/S13522310(00)00180-1, 2000.

Perrone, M. G., Gualtieri, M., Consonni, V., Ferrero, L., Sangiorgi, G., Longhin, E., Ballabio, D., Bolzacchini, E., and Camatini, M.: Particle size, chemical composition, seasons of the year and urban, rural or remote site origins as determinants of biological effects of particulate matter on pulmonary cells, Environ. Pollut., 176, 215-27, doi:10.1016/j.envpol.2013.01.012, 2013.

Perrone, M. G., Carbone, C., Faedo, D., Ferrero, L., Maggioni, A., Sangiorgi, G., and Bolzacchini, E.: Exhaust emissions of polycyclic aromatic hydrocarbons, $n$-alkanes and phenols from vehicles coming within different European classes, Atmos. Environ., 82, 391-400, 2014.

Platt, S. M., El Haddad, I., Zardini, A. A., Clairotte, M., Astorga, C., Wolf, R., Slowik, J. G., Temime-Roussel, B., Marchand, N., Ježek, I., Drinovec, L., Močnik, G., Möhler, O., Richter, R., Barmet, P., Bianchi, F., Baltensperger, U., and Prévôt, A. S. H.: Secondary organic aerosol formation from gasoline vehicle emissions in a new mobile environmental reaction chamber, Atmos. Chem. Phys., 13, 9141-9158, doi:10.5194/acp-13-91412013, 2013.

Pope, C. A., Ezzati, M., and Dockery, D. W.: Fine-particulate air pollution and life expectancy in the United States, New Engl. J. Med., 360, 376-386, 2009.

Ramanathan, V. and Feng, Y.: Air pollution, greenhouse gases and climate change: Global and regional perspectives, Atmos. Environ., 43, 37-50, doi:10.1016/j.atmosenv.2008.09.063, 2009.

Shorter, J. H., Herndon, S., Zahniser, M. S., Nelson, D. D., Wormhoudt, J., Demerjian, K. L., and Kolb, C. E.: Real-time measurements of nitrogen oxide emissions from in-use New York City transit buses using a chase vehicle, Environ. Sci. Technol., 39, 7991-8000, 2005.

Sharma, M., Kumar Agarwalb, A., and Bharathia, K. V. L.: Characterization of exhaust particulates from diesel engine, Atmos. Environ., 39, 3023-3028, 2005.

Shorter, J. H., Herndon, S. C., Zahniser, M. S., Nelson Jr., D. D., Wormhoudt, J., Demerjian, K. L., and Kolb, C. E.: Realtime measurements of nitrogen oxide emissions from in-use New York City transit buses using a chase vehicle, Environ. Sci. Technol., 39, 7991-8000, 2005.

Vinzents, P. S., Møller, P., Sørensen, M., Knudsen, L. E., Hertel, O., Jensen, F. P., Schibye, B., and Loft, S.: Personal exposure to ultrafine particles and oxidative DNA damage, Environ. Health Persp., 113, 1485-1490, 2005.

Vogt, R., Scheer, V., Casati, R., and Benter, T.: On-Road Measurement of Particle Emission in the Exhaust Plume of a Diesel Passenger Car, Environ. Sci. Technol., 37, 4070-4076, 2003. 
Wang, X., Westerdahl, D., Wu, Y., Pan, X., and Zhang, K. M.: Onroad emission factor distributions of individual diesel vehicles in and around Beijing, China, Atmos. Environ., 45, 503-513, 2011.

Wang, X., Westerdahl, D., Hu, J., Wu, Y., Yin, H., Pan, X., and Zhang, K. M.: On-road diesel vehicle emission factors for nitrogen oxides and black carbon in two Chinese cities, Atmos. Environ., 46, 45-55, doi:10.1016/j.atmosenv.2011.10.033, 2012.

Weilenmann, M., Bach, C., and Rüdy, C.: Aspect of instantaneous emission measurement, Int. J. Vehicle Des., 27, 94-104, 2001.
Weingartner, E., Keller, C., Stahel, W. A., Burtscher, H., and Baltensperger, U.: Aerosol emissions in a road tunnel, Atmos. Environ., 31, 451-462, 1997.

Weiss, M., Bonnel, P., Hummel, R., Manfredi, U., Colombo, R., Lanappe, G., Le Lijour, P., and Sculati, M.: Analysing on-road emissions of light-duty vehicles with Portable Emission Measurement Systems (PEMS), Publication Office of the European Union, Luxembourg, doi:10.2788/23820, 2011. 